\title{
THE OPTIMAL SCHEDULING MODEL FOR AGRICULTURAL MACHINERY RESOURCES WITH TIME-WINDOW CONSTRAINTS
}

\author{
Luo, X. W. ${ }^{*, * *} \&$ Zhang, L. Y.** \\ * School of Business Administration, Zhejiang University of Finance and Economics, P. R. China \\ ** Department of Logistics Technology, Zhejiang Technical Institute of Economics, P. R. China \\ ${ }^{* * *}$ School of Data Sciences, Zhejiang University of Finance and Economics, P. R. China \\ E-Mail: chet168@126.com
}

\begin{abstract}
Scheduling harvesting operations is very important for the agricultural machinery centres and the farmers in order to finish the harvesting work effectively. Most machinery owners schedule their farm machinery according to their own experiences, resulting in a big waste of agriculture resources. This paper attempts to schedule the use of agricultural machinery from the machinery resource centres under multi-farmland, multi-type situations considering time, spatial and weather factors as well as road factors in order to maximize efficiency of resource utilization. A modified fuzzy hybrid genetic algorithm is proposed to establish this scheduling model. An empirical study of an agricultural machinery association in Anhui province in China is illustrated and the results show that the models and the scheduling algorithm proposed in this study can improve the efficiency of utilization of the agricultural machinery resource centres and reduce the costs of agricultural machinery usage. (Received, processed and accepted by the Chinese Representative Office.)
\end{abstract}

Key Words: Scheduling Operations, Agricultural Machinery, Time Window, Multi-Type Machinery

\section{INTRODUCTION}

China is a very large agricultural country with extensive terrain. Similar crops have are produced at different times in different agricultural regions. Land management is decentralized because of the implementation of the household contract responsibility system and the rural economy is deficient. It is impossible for every rural household to buy large farm machinery. So trans-regional operations with Chinese characteristics, which is a unique farm machinery social service, has arisen. There are two cases of scheduling and allocating for farm machinery. In order to satisfy more economic interests, machinery owners choose the farmlands according to their own preferences independently. The farm machinery management department issues farm machinery demand information, which is provided by the three-level branch of the farm machinery management department. The demand information provided is macroscopic farmland information without specific scheduling and allocating schemes. Machinery owners schedule and allocate farm machinery by experience. How to select scheduling paths and farmland for obtaining the maximum profits is a difficult decision to make. When unforeseen events such as bad weather occur at harvest time, the farm machinery management department will organize farm machinery rapidly for completing the necessary tasks of farms in a limited amount of time in order to reduce losses. It is a difficult problem in terms of scheduling and allocating farm machinery to complete emergency tasks to solve for the farm machinery management department.

At present, the agricultural machinery management department has become very important in terms of the farm machinery socialization service [1-3]. The agricultural machinery management department can solve the contradiction between small-scale production and mechanization of large-scale operations of inter-district harvest work. However, there are still many important issues that need to be improved in the agricultural 
machinery socialization service. For example, harvest machinery operation information is incomplete and sometimes even inaccurate, which results in an unreasonable schedule of harvest machinery use $[4,5]$. As the implementation of the farm machinery subsidy policy in China, the number of various kinds of agricultural machinery increases. However, the market is limited, and the machinery, fuel oil, artificial costs all increase, so the profits decrease. Furthermore, the cost of the agricultural machinery schedule is high, while the whole operation efficiency of agricultural machinery is low. There are different agricultural situations varying among different countries, so the development of agricultural mechanization and the modes of operation are also different. The level of agricultural equipment and mechanization are relatively high in developed countries compared with the developing countries. With the development of agricultural modernization, many developed countries have established a relatively flawless agriculture socialization service system. Among these are the typical agricultural machinery management department in France, German agricultural machinery, agricultural mechanization of South Korea's camp, Japan's peasants association and agricultural machinery leasing companies in the United States. All of these agricultural machinery management organizations pay much attention to the harvesting scheduling operations and allocations [6].

Wu et al. [7] studied the time-windows based temporal and spatial scheduling model for agricultural machinery resources and the results of the model showed that it performed well in practice. A system of scheduling and allocating was proposed in [8] based on owners' choices.

Basnet et al. [9] discussed the harvest scheduling problem considering the contractor, as well as the cost, time, workers technical level and agricultural machinery operation service capability, under the condition of the limitation of contractors with multiple farms. The objective of the model was to minimize the operation time of each farm. The greedy tabu search algorithm was employed to resolve the problem. The harvest scheduling problem considered the contractor as similar to the resource constrained project scheduling problem. The scheduling problem for multi-farm harvesting was studied with the objective to minimize the total time of all the projects [10]. Each farm operations time is related to the distribution of agricultural machinery and workers. The dynamic programming problem based on probability was used to resolve the model, and arrive at the satisfactory solution. Ali et al. [11] discussed the field programming problem, which is the problem of scheduling between the harvester and tractors. The needs of the harvester and the requirements for the tractor should be coordinated with each other when working in the fields, and the tractor is needed when the harvester reached its specified capacity. There are two main questions to be considered: (1) the optimization scheduling for the harvesters and tractors, and (2) the transfer time of the harvested crop between cutter and tractors, and the overall objective was to minimize the total time.

Some previous studies have considered the problem with minimum time lags [12-15]. Other studies have assumed there are minimum time lags. The only exact procedure known was devised in [16]. However, it is not capable of solving problems of a practical size in a reasonable amount of time. In other studies, polynomial-time heuristics was applied for solving the scheduling problems [14-18]. The last technique is a neural network model based on heuristic methods [19-21].

Few references, if any, consider the time factor, spatial factors and weather and road factors. However, in agricultural operations, these are constraints which appear in the bound form of time period and network topology, causing difficulty in building and solving the agricultural model $[21,22]$. In this context, mathematical model for scheduling operations during harvesting are established under multi-farmland, multi-type situations considering the 
time factor, spatial factors and weather and road factors, and a modified fuzzy hybrid genetic algorithm is proposed to build this kind of scheduling model.

\section{PROBLEM DESCRIPTION}

In this context, we study all farm machinery resources centralized deployment problems under an agricultural machinery association. The agriculture machinery resource refers to the different kinds of agriculture harvesters. One agriculture harvester can be arranged to another farmland only after the work in the first farmland is completely finished.

The distribution diagram of agriculture machinery scheduling is shown as follows:

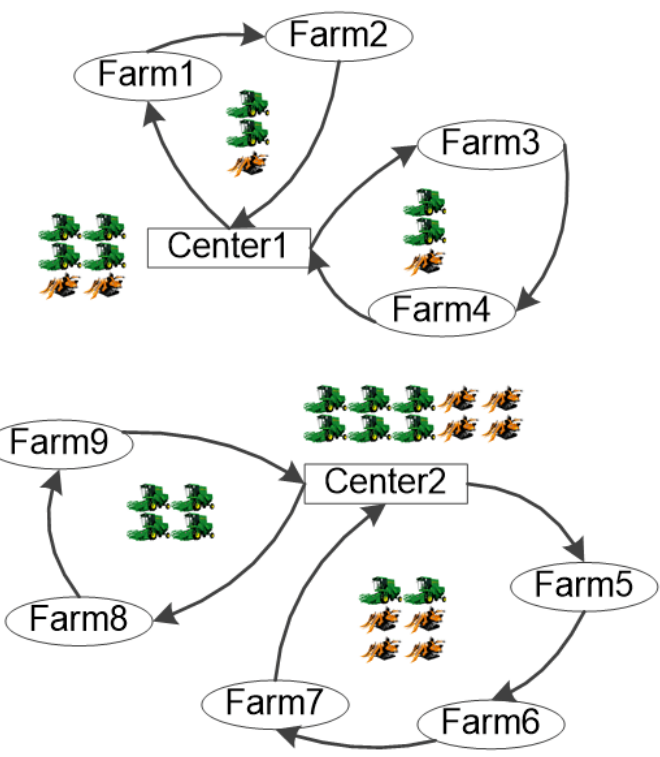

Figure 1: Distribution diagram of agriculture machinery scheduling.

The related assumptions are as follows:

(1) There are multiple agricultural machinery resource centres scattered in different locations, and the farmland coordinates are known and fixed;

(2) Each agricultural machinery resource centre has a certain number of various types of agricultural machinery and equipment, and the number and specifications (speed, fuel consumption, operation ability, etc.) of various types of agricultural machinery equipment are known and fixed, but are affected by many factors, such as weather, road conditions, etc. The speed, specific fuel consumption and operational capacity may differ depending on what types of tasks the agricultural machinery is performing;

(3) The farmlands are in different locations, and each farmland has a certain number of various types of agricultural machinery equipment, and the prices for equipment use are different for different farmlands;

(4) The location, price, operating time window and the requirements of agricultural machinery equipment for each farmland are known and fixed. The weather of different operating locations may be different in each time window, but the probability of occurrence of different scenarios is known (assuming the same farmland at the same time window only one weather conditions);

(5) All distances between agricultural machinery resource centres and farmlands are known, and there are no differences between each road, even though the road conditions of different times may differ; that is, agricultural vehicle traveling speed may be different, but the probability of traffic distribution is known (assuming the same farmland is only one road traffic situation at the same time window); 
(6) Different harvesting machines can work together in the same farmland, but if one machine works in one farmland, it cannot work in another farmland at the same time;

(7) The goal of the scheduling is maximizing the revenue brought about by use of the agricultural machinery.

\section{MATHEMATICAL MODEL}

For the CCPI system of our research, we assume that it adopts the pattern of geographically distributed visual teams to support the collaborative members (e.g. the intra-designers and customers) to implement the collaborative product innovation. Furthermore, the CCPI system opposes a stable collaborative relationship, thus there are existing close relationships among the collaborative teams and members.

All the symbols used in the model are shown in Table I as follows.

Table I: The symbols of model.

\begin{tabular}{|c|c|c|}
\hline No. & Symbol & Explanation of symbol \\
\hline 1 & $I$ & Total number of the agriculture machinery resource centres, $i=1, \ldots, I$ \\
\hline 2 & $J$ & Total number of farmlands, $j=1, \ldots, J$ \\
\hline 3 & $N$ & $\begin{array}{l}\text { Sum of the number of agriculture machinery resource centres and the number } \\
\text { of the farmlands, } n=1, \ldots, N, N=I+J, i=1, \ldots, I, j=1, \ldots, J\end{array}$ \\
\hline 4 & $P$ & Types of the agriculture machinery, $p=1, \ldots, P$ \\
\hline 5 & $M_{i p}$ & $\begin{array}{l}\text { The number of } p \text { type of the agriculture machinery in agriculture machinery } \\
\text { resource centre } I, k=1, \ldots, M_{i p}\end{array}$ \\
\hline 6 & $A_{j}$ & Area of farmland $j, j=1, \ldots, J$ \\
\hline 7 & $s_{j}$ & Income per unit area of farmland $j, j=1, \ldots, J$ \\
\hline 8 & $C_{j}$ & Cost per unit area of farmland $j, j=1, \ldots, J$ \\
\hline 9 & $d_{n n *}$ & Distance from centre from $n$ to $n^{*}, n=1, \ldots, N, n^{*}=1, \ldots, N$ \\
\hline 10 & $c_{p}$ & Unit mileage cost of the agriculture machinery $p, p=1, \ldots, P$ \\
\hline 11 & $r d_{j}$ & Penalty cost for late or early arrival to the farmland $j, j=1, \ldots, J$ \\
\hline 12 & $T F b_{j}$ & Actual start time of farmland $j, j=1, \ldots, J$ \\
\hline 13 & $T F e_{j}$ & Actual end time of farmland $j, j=1, \ldots, J$ \\
\hline 14 & $T F_{k j}$ & $\begin{array}{l}\text { Time length of the agriculture machinery } k \text { working in the farmland } j \text { actual } \\
\text { working hours, } j=1, \ldots, J\end{array}$ \\
\hline 15 & {$\left[t b_{j}, t e_{j}\right]$} & $\begin{array}{l}\text { Suitable harvest time window of farmland } j, j=1, \ldots, J \text {, suppose agriculture } \\
\text { machinery resource centres of time window is }[0,+\infty] \text {, the time window in days }\end{array}$ \\
\hline 16 & $v_{p}$ & $\begin{array}{l}\text { In ideal traffic conditions, } p \text {-type agriculture machinery's average running } \\
\text { speed, } p=1, \ldots, P\end{array}$ \\
\hline 17 & $Q_{p}$ & $\begin{array}{l}\text { In ideal weather conditions, } p \text {-type agriculture machinery's average daily } \\
\text { harvesting capacity, } p=1, \ldots, P\end{array}$ \\
\hline 18 & $t_{j}$ & $\begin{array}{l}\text { Farmland } j \text { traffic conditions within their time window (to destination } j \text { ), } \\
t_{j} \in[0,1], 1 \text { indicates an ideal situation, } 0 \text { indicates cannot operate. }\end{array}$ \\
\hline 19 & $w_{j}$ & $\begin{array}{l}\text { Weather conditions of farmland } j \text { within their time window, } w_{j} \in[0,1], 1 \\
\text { indicates an ideal situation, and } 0 \text { indicates cannot operate. }\end{array}$ \\
\hline 20 & $x_{i k p n n^{*}}$ & $\begin{array}{l}\text { Decision variable, } \\
x_{i k p n n *}=\left\{\begin{array}{ll}1, & \text { the machinery } k \text { of centre } i \text { from } n \text { to } n^{*} \\
0, & \text { others }\end{array}, n=1, \ldots, N, n^{*}=1, \ldots, N\right.\end{array}$ \\
\hline
\end{tabular}


The mathematical formulations of the model are shown as:

$$
\begin{aligned}
& \operatorname{maxZ}=\sum_{j=1}^{J} s_{j} \cdot A_{j}-\left(\sum_{i=1}^{I} \sum_{p=1}^{P} \sum_{k=1}^{M_{p}} \sum_{n^{*}=1}^{N} \sum_{n=1}^{N} x_{i k p n n^{*}} \cdot d_{n n^{*}} \cdot c_{p}+\sum_{j=1}^{J} A_{j} \cdot C_{j}+\left|t b_{j}-T F b_{j}\right| \cdot r d_{j}\right) \\
& \sum_{j=1}^{J} \sum_{k=1}^{M_{p}} \sum_{n^{*}=1}^{N} \sum_{n=1}^{N} x_{i k p n n^{*}} \leq M_{i p}, i=1, \ldots, I, \\
& T F b_{j}=\sum_{i=1}^{I} \sum_{k=1}^{M_{p}} \sum_{n=1}^{N} x_{i k p n j} \cdot\left(T F e_{n}+\frac{d_{n j}}{v_{p} \cdot t_{j}}\right), j=1, \ldots, J, \\
& T F_{k j}=\frac{A_{j}}{\sum_{i=1}^{I} \sum_{k=1}^{M_{p}} \sum_{n^{*}=1}^{N} \sum_{n=1}^{N} x_{i k p n n^{*}} \cdot Q_{p} \cdot w_{j}}, j=1, \ldots, J, \\
& T F e_{j}=T F b_{j}+T F_{k j}, j=1, \ldots, J, \\
& T F e_{j} \leq t e_{j}, j=1, \ldots, J, \\
& x_{i k p n n^{*}} \cdot\left|t e_{n}-t e_{n^{*}}\right| \leq \min \left\{T F_{k n}, T F_{k n^{*}}\right\}, k=1, \ldots, M_{i p}, p=1, \ldots, P, i=1, \ldots, I \text {, } \\
& x_{i k p n n^{*}} \in\{0,1\} .
\end{aligned}
$$

Eq. (1) refers to the objective function: Total revenue minus transportation costs minus the operations costs minus the delay or early arrival penalty. Eq. (2) refers to the constraint of the numbers of the agriculture machinery. Eq. (3) refers to the formula of the actual start time. Eq. (4) refers to the formula of the working time. Eq. (5) refers to the formula of the actual end time. Eq. (6) refers to the specified time before which all farmlands must complete the task. Eqs. (3)-(6) work together to assure that the farmland task is completed within the time window constraints. Eq. (7) refers to similar agricultural machinery and equipment. Eq. (8) refers to the decision variable value constraint.

\section{IMPROVED FUZZY GENETIC ALGORITHM}

The agricultural machinery distribution problem remains highly computationally complex, especially when dealing with large scales. It remains difficult to obtain exact solutions by an exact algorithm. Thus, this paper considers calculating the approximate optimal allocation of agricultural issues by using genetic algorithms. Genetic algorithm originally referred to a number of phenomena of evolutionary biology, including genetic mutations, natural selection, hybridization, etc. It is possible for GA fitness function to arrive at a local optimum when choosing mistaken cross-mutation strategies and fitness functions, but it cannot reach the global optimum. In order to control the shortcoming of the genetic algorithm of easily falling into a local optimal solution, we designed a method of controlling the adaptive genetic algorithm crossover and mutation process of fuzzy logic rules. In the algorithm iterative process, the crossover and mutation probability were dynamically adjusted by fuzzy logic controller to avoid premature convergence and improve the convergence speed. This accorded to the relationship among the best fitness of the current population, average fitness and be cross the degree of variability of individual fitness to control the crossover and mutation probability. The flow chart of fuzzy genetic algorithm is shown in Fig. 2. 


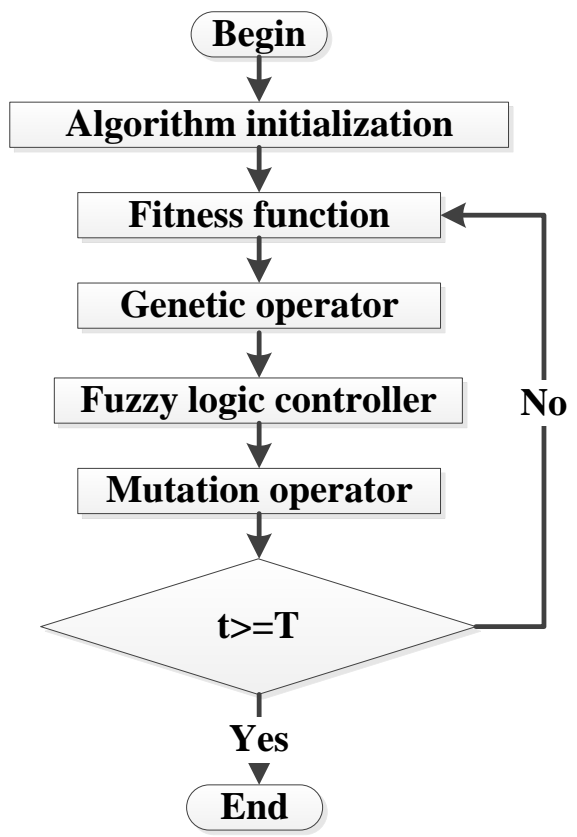

Figure 2: The schematic diagram of operation of fuzzy genetic algorithm.

(1) Encoding

GA cannot directly calculate the parameters of the problem space, so it needs to transfer them to the chromosome or individual with a certain gene structure in genetic space. This paper employs the simple binary digital coding method, and the sample with ten farmlands and two centres of the agricultural machinery is shown in Fig. 3.

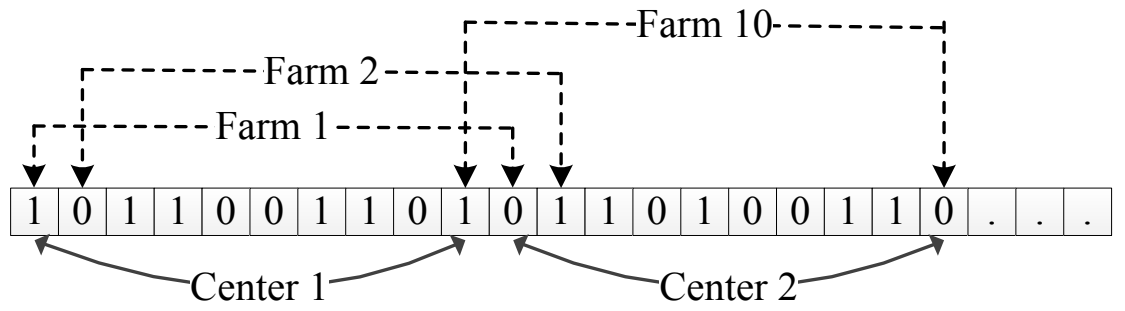

Figure 3: Binary digit encoding.

(2) Fitness function

The objective function is identified as the fitness function. However, in most of the situations, the fitness value is small and cannot be adjusted, and the differences of fitness values are large.

(3) Selection operator

The objective of selection is for the next generation to inherit from the optimized individual (or solution) or through matching cross to produce new individual genetics to future generations. In this paper, the simplest and the most commonly used roulette wheel selection method is selected.

(4) Crossover operator

Two crossover points are selected randomly, and then we need to copy the segment between the crossover points from the first parent. The elements are copied to the offspring in the order they appear since the second crossover point in order to avoid repetition. The steps of the crossover operator are shown in Figs. 4 and 5. 


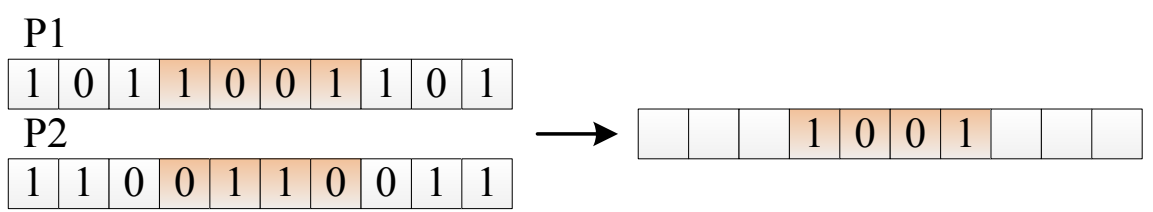

Figure 4: Crossover operator.

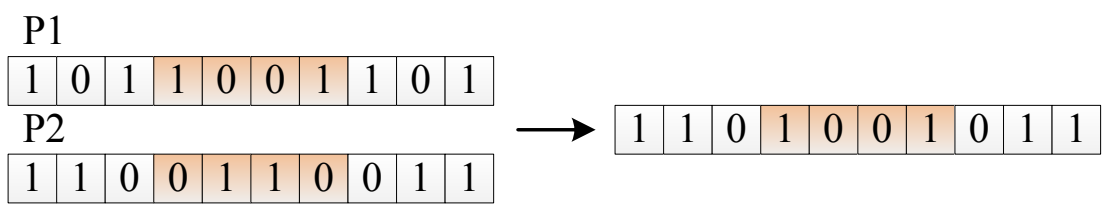

Figure 5: Crossover operator.

(5) Mutation operator

It works by selecting two positions in the string randomly and reversing the order, as shown in Fig. 6.

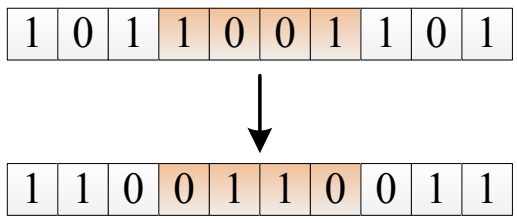

Figure 6: Mutation operator.

(6) Adaptive-fuzzy logic module

In this paper, we propose a fuzzy logic rule based on the value of chromosome fitness, as well as value variation of population average fitness. $F$ refers to the fitness value of the current chromosome. $\bar{F}_{r}$ implies the average fitness value of population $r . F_{\max }$ and $F_{\min }$ represent the fitness values of the best and the worst chromosomes in the current population respectively. The input parameters are shown in Table II.

Table II: Input parameters of fuzzy logic module.

\begin{tabular}{|c|c|}
\hline Input parameter & Parameter explanation \\
\hline$\Delta \bar{F}$ & $\Delta \bar{F}=\frac{\left(\overline{F_{r}}-\overline{F_{r-1}}\right)}{\overline{F_{r-1}}}, \Delta \bar{F} \in[0,1], r>1$ \\
\hline$\alpha$ & $\alpha=\frac{\left(F_{\max }-F\right)}{\left(F_{\max }-F_{\min }\right)}, \alpha \in[0,1]$ \\
\hline
\end{tabular}

Nine sematic values are included in the fuzzy logic module. The triangle membership function is employed, and the fuzzy logic rules are shown in Table III based on the triangle fuzzy membership function.

\section{SIMULATION ANALYSIS}

There are two parts in the simulation analysis: one is based on simulation trials of testing functions for improving the effectiveness and efficiency of fuzzy genetic algorithm; the second one is the simulation based on the actual data. 
Table III: The fuzzy logic rules of mutation probability.

\begin{tabular}{|c|c|c|c|c|c|c|c|c|c|}
\hline & ES & VS & $\mathbf{S}$ & RS & $\mathbf{M}$ & $\mathbf{R L}$ & $\mathbf{L}$ & VL & $\mathbf{E L}$ \\
\hline ES & $\mathrm{M}$ & $\mathrm{RL}$ & $\mathrm{RL}$ & $\mathrm{L}$ & $\mathrm{L}$ & VL & VL & EL & EL \\
\hline VS & $\mathrm{RS}$ & $\mathrm{M}$ & $\mathrm{RL}$ & RL & $\mathrm{L}$ & $\mathrm{L}$ & VL & VL & EL \\
\hline $\mathbf{S}$ & $\mathrm{RS}$ & $\mathrm{RS}$ & $\mathrm{M}$ & $\mathrm{RL}$ & $\mathrm{RL}$ & $\mathrm{L}$ & $\mathrm{L}$ & $\mathrm{VL}$ & VL \\
\hline $\mathbf{R S}$ & S & $\mathrm{RS}$ & $\mathrm{RS}$ & $\mathrm{M}$ & $\mathrm{RL}$ & $\mathrm{RL}$ & $\mathrm{L}$ & $\mathrm{L}$ & VL \\
\hline $\mathbf{M}$ & S & S & $\mathrm{RS}$ & RS & $\mathrm{M}$ & $\mathrm{RL}$ & $\mathrm{RL}$ & $\mathrm{L}$ & $\mathrm{L}$ \\
\hline RL & VS & S & S & $\mathrm{RS}$ & RS & $\mathrm{M}$ & $\mathrm{RL}$ & $\mathrm{RL}$ & $\mathrm{L}$ \\
\hline $\mathbf{L}$ & VS & VS & $\mathrm{S}$ & $\mathrm{S}$ & $\mathrm{RS}$ & $\mathrm{RS}$ & $\mathrm{M}$ & $\mathrm{RL}$ & RL \\
\hline VL & ES & VS & VS & $S$ & $\mathrm{~S}$ & $\mathrm{RS}$ & $\mathrm{RS}$ & $\mathrm{M}$ & $\mathrm{RL}$ \\
\hline $\mathbf{E L}$ & ES & ES & VS & VS & $\mathrm{S}$ & S & RS & $\mathrm{RS}$ & $\mathrm{M}$ \\
\hline
\end{tabular}

In order to demonstrate the process of adaptive fuzzy logic rules change, this paper improved performance of the fuzzy genetic algorithm by Rastrigin's function tests. Rastrigin's function has two independent variables as follows:

$$
\operatorname{Ras}\left(x_{1}, x_{2}\right)=20+x_{1}^{2}+x_{2}^{2}-10\left(\cos 2 \pi x_{1}+\cos 2 \pi x_{x}\right)
$$

There are many local minima points in the graphical representation of Rastrigin's function but only one global minimum point which is $[0,0]$. As continuous variables, we substituted real coding for binary coding in the fuzzy genetic algorithms during tests, while the other genetic manipulation strategies remain constant. The improved optimal solution is 0.0166 . Fuzzy logic rules of fuzzy genetic algorithm depend on the fitness numbers. The changes in average fitness values for the population and the best individuals are shown in Fig. 7.

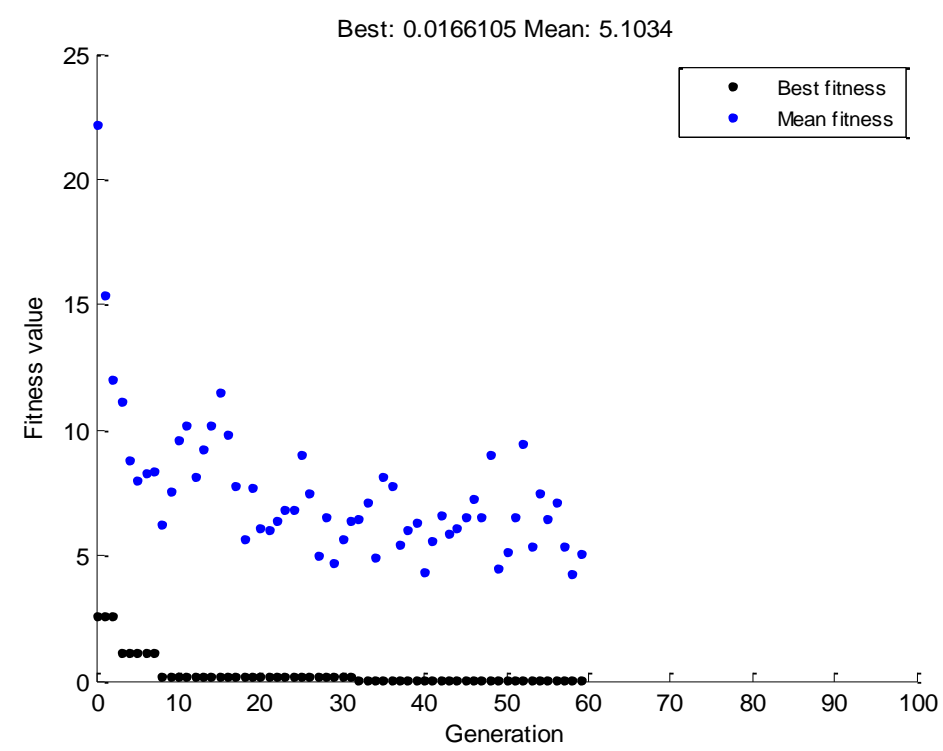

Figure 7: Changes in average fitness values with the improved fuzzy GA.

In order to further compare the fuzzy genetic algorithm with the classical genetic algorithm in computational effects and speed, we used three algorithms of De Jong function, Shaffer function and Shubert function respectively.

De Jong function is defined as follows: 


$$
\left\{\begin{array}{l}
f_{D J}\left(x_{1}, x_{2}, x_{3}\right)=\sum_{i=1}^{3} x_{i}^{2} \\
-5.12 \leq x_{i} \leq 5.12, i=1,2,3
\end{array}\right.
$$

Shaffer function is:

$$
\left\{\begin{array}{l}
f_{S R}\left(x_{1}, x_{2}\right)=0.5+\frac{\sin \sqrt[2]{x_{1}^{2}+x_{2}^{2}}-0.5}{\left[1.0+0.001\left(x_{1}^{2}+x_{2}^{2}\right)\right]^{2}} \\
-100 \leq x_{i} \leq 100, i=1,2
\end{array}\right.
$$

Shubert function is:

$$
\left\{\begin{array}{l}
f_{S T}\left(x_{1}, x_{2}\right)=\sum_{i=1}^{5} i \cos \left[(i+1) x_{1}+i\right] \cdot \sum_{i=1}^{5} i \cos \left[(i+1) x_{2}+i\right] \\
-10 \leq x_{i} \leq 10, i=1,2
\end{array}\right.
$$

The test results are shown in Table IV.

Table IV: Calculation results based on the test function.

\begin{tabular}{|c|c|c|c|c|c|}
\hline \multirow{2}{*}{ Test function } & \multicolumn{3}{|c|}{ The calculation results } & Optimal & \multirow{2}{*}{ value } \\
\cline { 2 - 5 } & GA & Fuzzy GA & Improved fuzzy GA & \\
\hline De Jong function & 0.7923 & 0.0647 & 0.0012 & 0 & 0.0012 \\
\hline Shaffer function & 1.6509 & 0.7538 & 0.0835 & 0 & 0.0835 \\
\hline Shubert function & -159.2319 & -179.8538 & -186.0215 & -186.731 & 0.7095 \\
\hline
\end{tabular}

The test and application of the agricultural machinery scheduling model was studied in Anhui province in China. The harvesting operations information in the previous ten years was collected. The agricultural machinery group consists of eight centres of agricultural machinery, with each centre having between ten and 20 large, medium and small pieces of agricultural machinery. With the development of the scale of operation, harvesting operations covered from 84 farmlands in 2010 to 167 in 2015. The total area of fields spans nearly 500 $\mathrm{km}$, and all the farmlands must be harvested within a 28 day period. Since Anhui province is located in the region that is rainy in the harvest season, and because its farmland consists of slopes and hilly terrain, the work environment is considerably affected by weather factors. Therefore, it is essential to study and understand the conditions of the harvesting time window. In this paper, hard time window constraints are considered. In order to facilitate comparison, per unit cost of harvest and other related expenses are calculated with the actual values. We compare the harvesting costs with the optimized results, which are shown in Table V.

Table V: Results of empirical study.

\begin{tabular}{|c|c|c|c|c|}
\hline \multirow{2}{*}{ Year } & \multirow{2}{*}{ Area } & \multicolumn{2}{|c|}{ Costs } & \multirow{2}{*}{$\begin{array}{c}\text { Cost reduction } \\
\text { (\%) }\end{array}$} \\
\cline { 3 - 4 } & & Actual costs & Optimized costs & 21.55 \\
\hline $\mathbf{2 0 1 0}$ & 480.6 & 13509.24 & 10598.32 & 21.69 \\
\hline $\mathbf{2 0 1 1}$ & 579.2 & 15934.67 & 12479.21 & 19.32 \\
\hline $\mathbf{2 0 1 2}$ & 684.9 & 21479.24 & 17328.65 & 18.94 \\
\hline $\mathbf{2 0 1 3}$ & 795.3 & 25846.35 & 20951.23 & 16.21 \\
\hline $\mathbf{2 0 1 4}$ & 856.4 & 29857.45 & 25016.98 & 18.99 \\
\hline Average & 679.3 & 21325.39 & 17274.88 & \\
\hline
\end{tabular}


It can be seen from the optimization result of the empirical analysis that the average annual cost savings was around $20 \%$ from 2010 to 2014, and that the operation cost reduction is smaller year by year (from $21.55 \%$ in 2010 to $18.99 \%$ in 2014). As the development of mechanization level and personnel operating level, farmland operation cost has also been reduced, so the agricultural equipment scheduling optimization space is narrowing. However, an $18.99 \%$ reduction in costs is still considerably high, and even as little as a $10 \%$ reduction would still be profitable.

\section{CONCLUSION}

This paper attempts to schedule the use of agricultural machinery by the machinery resource centres under multi-farmland, multi-type situations, considering time, spatial and weather factors as well as the road factors in order to maximize efficiency of resource utilization. A modified fuzzy hybrid genetic algorithm is proposed to resolve this kind of scheduling model. An empirical study of an agricultural machinery association in Anhui province in China is illustrated and the results show that the models and the scheduling algorithm proposed in this study can improve the efficiency of agricultural utilization of the farm machinery and reduce the cost of agricultural machinery usage as high as $18.99 \%$ per year.

\section{ACKNOWLEDGEMENTS}

The work has been funded by the Research Funds for Zhejiang Province Philosophy Social Sciences key Research Base of Zheshang Research Center project (14JDZS02YB); Ministry of Education of the Republic of China (15YJA630044) and Zhejiang Gongshang University Visiting Project (FX2014182).

\section{REFERENCES}

[1] Chou, S.; Jiang, B.; Liao, X.; Fu, J. (2007). Research on household contract land management and model of farm machinery service organization, Modern Agricultural Equipment, Vol. 7, No. $1,44-47$

[2] Liao, X.; Gao, Y.; Jiang, B.; Huang, G. (2008). Development situation and prospect forecast of the harvesting wheat across different countries area, Journal of Agricultural Mechanization Research, Vol. 24, No. 2, 10-14

[3] Liu, Z. (2008). Analysis on influential factors of the development of China's agricultural service organizations, Proceedings of China Agricultural Machinery Association 2008 Annual Conference, 39-41

[4] Zhang, X.; Lu, M. (2005). Analysis of the economic benefit on harvesting wheat across different countries area, Journal of Agricultural Mechanization Research, Vol. 21, No. 6, 100-103

[5] Yu, L.; Xiao, X. (2007). Current situation and development trend of agricultural mechanization on domestic and overseas, Journal of Hubei Agricultural Mechanization Research, Vol. 6, 36-37

[6] Zhang, X. (2006). Study on the service system in trans-regional harvesting wheat using combine harvester, Agricultural University of China, Beijing, 7-90

[7] Wu, C.; Cai, Y.; Luo, M.; Su, H.; Ding, L. (2013). Time-windows based temporal and spatial scheduling model for agricultural machinery resources, Journal of Agricultural Machinery, Vol. 44, No. 5, 237-240

[8] Zhang, F.; Teng, G.-F.; Ma, J.-B.; Chang, S.-H. (2012). Farm machinery scheduling and allocating based on heuristic priority rules, Transactions of the Chinese Society of Agricultural Engineering (Transactions of the CSAE), Vol. 28, No. 10, 78-85

[9] Basnet, C. B.; Foulds, L. R.; Wilson, J. M. (2006). Scheduling contractors' farm-to-farm crop harvesting operations, International Transactions in Operational Research, Vol. 13, No. 1, 1-15, doi: $10.1111 / \mathrm{j} .1475-3995.2006 .00530 . \mathrm{x}$ 
[10] Foulds, L. R.; Wilson, J. M. (2005). Scheduling operations for the harvesting of renewable resources, Journal of Food Engineering, Vol. 70, No. 3, 281-292, doi:10.1016/ j.jfoodeng.2003.12.009

[11] Ali, O.; Verlinden, B.; Van Oudheusden, D. (2009). Infield logistics planning for crop-harvesting operations, Engineering Optimization, Vol. 41, No. 2, 183-197, doi: $\underline{10.1080 /}$ $\underline{03052150802406540}$

[12] Bartusch, M.; Moehring, R. H.; Radermacher, F. J. (1988). Scheduling project networks with resource constraints and time windows, Annals of Operations Research, Vol. 16, No. 1, 199-240, doi: $\underline{10.1007 / \mathrm{bf} 02283745}$

[13] Brucker, P.; Drexl, A.; Moehring, R.; Neumann, K.; Pesch, E. (1999). Resource-constrained project scheduling: Notation, classification, models, and methods, European Journal of Operational Research, Vol. 112, No. 1, 3-41, doi:10.1016/s0377-2217(98)00204-5

[14] Neumann, K.; Zimmermann, J. (1999). Methods for resource-constrained project scheduling with regular and nonregular objective functions and schedule-dependent time windows, Weglarz, J. (Ed.), Project scheduling: Recent models, algorithms, and applications, Springer Science+Business Media, New York, 261-287, doi:10.1007/978-1-4615-5533-9 12

[15] Neumann, K.; Zimmermann, J. (1999). Resource levelling for projects with schedule-dependent time windows, European Journal of Operational Research, Vol. 117, No. 3, 591-605, doi: $10.1016 / \mathrm{s} 0377-2217(98) 00272-0$

[16] Neumann, K.; Zimmermann, J. (2000). Procedures for resource levelling and net present value problems in project scheduling with general temporal and resource constraints, European Journal of Operational Research, Vol. 127, No. 2, 425-443, doi:10.1016/s0377-2217(99)00498-1

[17] Brinkmann, K.; Neumann, K. (1996). Heuristics procedures for resource-constrained project scheduling with minimal and maximal time lags: the resource-levelling and minimum project-duration problems, Journal of Decision Systems, Vol. 5, No. 1-2, 129-155, doi: $10.1080 / 12460125.1996 .10511678$

[18] Qi, Y.-N.; Tang, M.-C.; Zhang, M. (2014). Mass customization in flat organization: The mediating role of supply chain planning and corporation coordination, Journal of Applied Research \& Technology, Vol. 12, No. 2, 171-181, doi:10.1016/s1665-6423(14)72333-8

[19] Harris, R. (1990). Packing method for resource levelling (Pack), Journal of Construction Engineering and Management, Vol. 116, No. 2, 331-350, doi:10.1061/(ASCE)07339364(1990)116:2(331)

[20] Moder, J. J.; Phillips, C. R.; Davis, E. W. (1983). Project Management with CPM, PERT and Precedence Diagramming, $3^{\text {rd }}$ ed., Van Nostrand Reinhold, New York

[21] Takamoto, M.; Yamada, N.; Kobayashi, Y.; Nonaka, H. (1995). Zero-one quadratic programming algorithm for resource levelling of manufacturing process schedules, Systems and Computers in Japan, Vol. 26, No. 10, 68-76, doi:10.1002/scj.4690261007

[22] Sessions, J.; Sessions, J. B. (1991). Tactical harvest planning using SNAP 2.03, Proceedings of the Conference of the International Union of Forestry Research Organizations, 824-831 